\section{Analysis of Recent Enrollment Trends and Recruiting Strategies in Horticulture}

\author{
W. Timothy Rhodus ${ }^{1}$ \\ Department of Horticulture, The Ohio State University, Columbus, \\ $\mathrm{OH} 43210$
}

Additional index words. education

\begin{abstract}
A survey of bachelor degree programs in the United States indicated that horticultural enrollment declined $4.4 \%$ between 1986 and 1988. Programs that increased enrollment (39\% of those responding) were more likely to use various recruitment materials and activities than were those with declining or no change in enrollment (48\% and $13 \%$, respectively). Supply of students and time required to recruit were most often reported as high priority issues. The percentage of new majors recently graduated from high school had declined in $43 \%$ of the programs, but increases were reported in students age 22 and above, no prior horticultural experience, and interested in a part-time program. Both the direct approach, open house or personal visit, and the indirect approach, students and alumni promoting the program, were reported as effective recruitment activities.
\end{abstract}

Undergraduate enrollment in horticulture can be affected by an aggressive recruiting strategy. This was demonstrated at Rutgers Univ., New Brunswick, N. J., where a college-wide program that provided prospective students, their parents, teachers, and counselors the opportunity to see the facilities and interact with university professors resulted in increased enrollment (Childers, 1989b). Other examples of progressive recruiting programs in North Carolina, Ohio, Michigan, Texas, California, and Maine are presented in Hundley (1988).

Given that each horticulture program is unique in terms of location, size, and human and physical resources, the success of a recruiting strategy depends on the choice of specific materials and/or activities that most effectively market the program. However, since few horticulture faculty are trained in developing marketing plans, the end result may be a series of well-intentioned efforts that fail to realize full potential. Nefstead (1988) discussed specific steps that were taken to market the Agricultural Sales and Marketing program at the Univ. of Minnesota Technical College. The result of this effort was an increase in enrollment.

Nevertheless, recruitment case studies do not provide insight into relationships that may exist between enrollment trends and the use of specific recruitment strategies. The present study evaluates the success of various recruitment strategies for horticulture. Specific objectives of this study were to: a) identify whether trends in horticulture enrollment differed according to the location or size of

Received for publication 31 Aug. 1989. Salaries and research support provided by state and federal funds appropriated to the Ohio Agricultural Research and Development Center, The Ohio State Univ. Manuscript no. 92-90.

${ }^{1}$ Assistant Professor, Depts. of Horticulture and Agricultural Economics and Rural Sociology. the program; b) identify whether changes in enrollment in horticulture programs between 1986 and 1988 were influenced by the use of specific recruitment materials and/or activities; and c) identify critical issues that are likely to affect the development of future recruiting strategies.

A survey questionnaire was developed and mailed in Apr. 1989 to 90 institutions offering horticulture bachlor degree programs. Institutions listed by Childers (1989a) were chosen for this study. A follow-up letter was mailed 3 weeks later and a second questionnaire was mailed to all nonrespondents in June 1989.

Undergraduate enrollment figures were reported for each program by area of specialization, i.e., floriculture, landscape horticulture, fruits and vegetables, and other. Programs were classified into size categories based on the total number of undergraduate students enrolled for 1988. They were: <23, between 23 and 52, between 53 and 81, and cialization.

${ }^{7}$ Mean change in enrollment between 1986 and 1988.

y Mean separation within each criterion by LSD, $P=0.05$.

${ }^{x}$ Regions are those used by the USDA-CSRS classification.
$>81$ students. Each range represented $\approx 25 \%$ of the respondents. Programs were also categorized according to the change in enrollment between 1986 and 1988: increasing, decreasing, or no change. This time period was chosen to capture the most recent information on enrollment trends. Comparing 1988 to 1984 would more likely have shown a negative trend. If departments are going to be successful in reversing the downward trend in enrollment, then more recent time periods need to be examined. An analysis of variance (ANOVA) was conducted to identify whether significant differences existed in recent enrollment trends among different regions of the country, sizes of program, or areas of specialization.

Each program was asked to identify the extent to which they used the 25 types of recruitment materials and activities listed in Table 3. A $\chi^{2}$ test was used to identify whether enrollment trends and use of recruitment materials and/or activites were related. A discriminant analysis was conducted to identify the impact on enrollment trend due to each of the materials and activities. Discriminant coefficients were used to predict enrollment trends for each program. Percentage of correctly predicted trends was examined.

The survey also generated information useful for developing future recruitment strategies. Each respondent was asked to: 1) rank the importance of 10 issues (Table 5) on future enrollment; 2) identify how the percentage of students declaring horticulture as a major from eight backgrounds had changed over the past 5 years (Table 6); and 3 ) identify in an open-ended question their most effective recruitment activity. Results of the first two questions were analyzed using a $\chi^{2}$ test for differences among programs. Recruitment activities identified for the third question were condensed into major categories of activities that contained the most often quoted responses. All analyses were conducted using SPSS/PC + for the personal computer (Norusis, 1986).

Enrollment trends. A total of $60(67 \%)$ usable surveys were received. Response rates

Table 1. Total undergraduate enrollment in horticulture by region, program size, and area of spe-

\begin{tabular}{|c|c|c|c|c|}
\hline Criterion & 1984 & 1986 & 1988 & $\begin{array}{c}\text { Change } x, y \\
(\%)\end{array}$ \\
\hline Overall & 3344 & 2965 & 2836 & -4.4 \\
\hline \multicolumn{5}{|l|}{ Region $\mathbf{x}$} \\
\hline Northeast & 105 & 131 & 119 & $-11.6 \mathrm{a}$ \\
\hline North Central & 856 & 726 & 667 & $-7.3 \mathrm{a}$ \\
\hline West & 1007 & 836 & 769 & $-6.2 \mathrm{a}$ \\
\hline South & 1376 & 1272 & 1281 & $-3.9 a$ \\
\hline \multicolumn{5}{|l|}{ Program size } \\
\hline $1-22$ & 253 & 205 & 169 & $-8.4 \mathrm{a}$ \\
\hline $23-52$ & 451 & 377 & 358 & $-2.2 \mathrm{a}$ \\
\hline $53-81$ & 1142 & 927 & 844 & $-6.5 a$ \\
\hline$>81$ & 1498 & 1456 & 1465 & $1.7 \mathrm{a}$ \\
\hline \multicolumn{5}{|l|}{ Specialization } \\
\hline Floriculture & 454 & 349 & 281 & $-8.7 \mathrm{a}$ \\
\hline Landscape horticulture & 1117 & 1052 & 1094 & $12.2 \mathrm{a}$ \\
\hline Fruit and vegetable & 199 & $126^{\circ}$ & 99 & $-3.3 \mathrm{a}$ \\
\hline
\end{tabular}


Table 2. Change in enrollment between 1986 and 1988 by region and program size.

\begin{tabular}{lccc}
\hline Criterion $^{2}$ & $\begin{array}{c}\text { Decreasing } \\
(\%)\end{array}$ & $\begin{array}{c}\text { Increasing } \\
(\%)\end{array}$ & $\begin{array}{c}\text { No change } \\
(\%)\end{array}$ \\
\hline Overall & 47.8 & 39.1 & 13.0 \\
Region & & & 0.0 \\
$\quad$ Northeast & 100.0 & 0.0 & 0.0 \\
Northcentral & 54.5 & 45.5 & 11.1 \\
West & 44.4 & 44.4 & 15.0 \\
South & 45.0 & 40.0 & 28.6 \\
Program size & & & 10.0 \\
1-22 & 42.9 & 28.6 & 8.3 \\
$23-52$ & 50.0 & 40.0 & 0.0 \\
$53-81$ & 66.7 & 25.0 & 70.0 \\
$>81$ & 30.0 & & \\
\hline
\end{tabular}

${ }^{2} \chi^{2}$ test indicates no significant differences among regions or program sizes.

Table 3. Use of recruitment materials and change in enrollment between 1986 and 1988.

\begin{tabular}{|c|c|c|c|}
\hline Recruitment materials & $\begin{array}{c}\text { Decreasing } \\
(\%)\end{array}$ & $\begin{array}{c}\text { Increasing } \\
(\%)\end{array}$ & $\begin{array}{c}\text { No change } \\
(\%)\end{array}$ \\
\hline Handbook describing dept. programs & 96 & 100 & $83^{z}$ \\
\hline Handbook describing faculty research programs & 48 & 44 & $50^{z}$ \\
\hline Handbook describing scholarships and awards & 65 & 78 & $67^{2}$ \\
\hline Handbook describing career opportunities & 82 & 94 & $67^{2}$ \\
\hline Video tape describing dept. programs & 13 & 11 & $0^{z}$ \\
\hline Video tape describing college programs & 41 & 67 & $50^{2}$ \\
\hline Video tape describing career opportunities & 26 & 39 & $17^{2}$ \\
\hline Dept. display used at public events & 78 & 83 & $67^{2}$ \\
\hline Poster describing departmental programs & 39 & 44 & $50^{\mathrm{z}}$ \\
\hline Dept. advertising in magazines/newspapers & 22 & 6 & $33^{z}$ \\
\hline Dept. advertising on radio or television & 0 & 0 & $0^{\mathrm{z}}$ \\
\hline Send unsolicited letters to prospective students & 65 & 59 & $50^{2}$ \\
\hline Advise undecided majors about horticulture & 87 & 100 & $67^{2}$ \\
\hline Meet with other college career counselors & 65 & 82 & $33^{2}$ \\
\hline Meet with high school guidance counselors & 35 & 82 & $33^{y}$ \\
\hline Participate in college career day & 74 & 77 & $83^{2}$ \\
\hline Participate in high school career day & 61 & 94 & $33^{y}$ \\
\hline Participate in elementary and junior high career day & 9 & 35 & $0^{y}$ \\
\hline Provide dept. information at public events & 82 & 100 & $67^{\mathrm{z}}$ \\
\hline Provide dept. information at industry trade shows & 74 & 59 & $67^{\mathrm{z}}$ \\
\hline Develop programs involving alumni in recruitment & 17 & 41 & $17^{2}$ \\
\hline Develop programs involving industry in recruitment & 23 & 29 & $0^{\mathbf{z}}$ \\
\hline Provide travel funds for prospective students & 9 & 12 & $0^{\mathbf{z}}$ \\
\hline Conduct tours for prospective students & 83 & 100 & $67^{2}$ \\
\hline Invite high school students to college for a day & 35 & 71 & $50^{2}$ \\
\hline
\end{tabular}

${ }^{2} \chi^{2}$ test indicates no significant differences among categories.

${ }^{y} \chi^{2}$ statistic significant at $P=0.05$ among categories.

Table 4. Diseriminant function coefficients used to classify enrollment trends.

\begin{tabular}{lrr}
\hline \hline & Fn $1^{\mathrm{z}}$ & Fn $2^{\mathrm{y}}$ \\
\hline Constant & -8.14 & -2.63 \\
Handbook describing dept. programs & 4.87 & 3.08 \\
Video tape describing dept. programs & 0.58 & -1.20 \\
Dept. advertising used in magazines or newspapers & -1.24 & 0.16 \\
Advise undecided majors about horticulture & 1.45 & -0.11 \\
Meet with other college career counselors & 0.74 & 0.94 \\
Meet with high school guidance counselors & 1.48 & -0.05 \\
Participate in high school "career day" & 1.63 & 0.45 \\
Provide dept. information at industry trade shows & -0.64 & 0.69 \\
Develop programs involving alumni in recruitment & 1.95 & 0.36 \\
Provide travel funds for prospective students & 1.56 & 0.47 \\
Invite high school students to attend college & -1.02 & -2.07 \\
\hline
\end{tabular}

${ }^{\mathrm{x}}$ Fn $1: \chi^{2}=50.41 ; 22 \mathrm{df} ;$ significance $=0.0005 ;$ Canonical correlation $=0.85$; Eigenvalue $=2.58$; Wilks Lambda $=0.24$.

${ }_{\mathrm{y} F n} 2: \ddot{\chi}^{2}=5.79 ; 10 \mathrm{df}$; significance $=0.83$; Canonical correlation $=0.39$; Eigenvalue $=0.20$; Wilks Lambda $\fallingdotseq 0.85$.

from the four major U.S. Dept. of Agriculture regions were: Northeast $73 \%$, North Central $72 \%$, South $69 \%$, and West $58 \%$. Enrollment figures reported by the 46 schools that reported their enrollment for all 3 years indicate that enrollment in horticulture was the South between 1986 and 1988. Decreases in enrollment were observed between 1984 and 1986 in all four program size categories and three of the four categories between 1986 and 1988. Only the large departments (81 or more students) exhibited any growth in enrollment between 1986 and 1988 .

Trends in undergraduate enrollment by program specialty for the period 1986 to 1988 indicate an average decrease of $8.7 \%$ in floriculture, a $12 \%$ increase in landscape horticulture, and a $3.3 \%$ decrease in pomology and olericulture. When converted to share of total enrollment, that in floriculture dropped from $31 \%$ to $27 \%$, that in landscape horticulture increased from $56 \%$ to $61 \%$, and that in pomology and olericulture declined from $13 \%$ to $11 \%$. These trends coincide with previous research reported for-floriculture by Widmer (1988) but also suggest that opportunities for expanding enrollment exist within the area of landscape horticulture. An ANOVA did not reveal statistically significant differences between enrollment trends and area of specialization.

Overall, enrollment declined between 1986 and 1988 in nearly half of the programs, increased in $\approx 40 \%$, and remained the same in the rest (Table 2). However, the frequency of growth was not statistically different among regions or program sizes. Interestingly, $70 \%$ of the programs with $>81$ students had increased in enrollment.

Recruitment materials and activities. The percentage of programs using various recruitment materials and activities was determined separately for the three enrollment trend categories (Table 3). Programs that experienced a decrease in enrollment were generally using the various materials and activities to a lesser extent than programs that increased in enrollment. A series of $\chi^{2}$ tests was conducted to determine whether differences existed in use of materials or activities among the three trend categories. No differences were found in the use of recruitment materials, but differences were found to exist within three recruitment activities: a) meetings with high school guidance counselors, b) participation in high school career day, and c) participation in elementary and junior high career day (Table 3 ). These findings suggest that participating in career-influencing events for young people will benefit horticulture programs, even though the benefit may be delayed for several years.

A discriminant analysis was conducted to differentiate enrollment trends by key recruitment materials and activities. Eleven of the 25 materials and activities were found to be significant and used to estimate two discriminant functions (Fn) (Table 4). Final scores on Fn 1 for the three groups were: 1.76 for increasing enrollment, -0.73 for decreasing, and -2.57 for no change. Scores on Fn 2 were: -0.20 for increasing, 0.39 for decreasing, and -0.76 for no change. Discriminant scores were calculated for each program and then used to test the ability of the two functions to accurately predict enrollment trends. Prediction accuracy was 
Table 5. Priority of issues affecting future enrollment.

\begin{tabular}{lccr}
\hline \hline & $\begin{array}{c}\text { High } \\
(\%)\end{array}$ & $\begin{array}{c}\text { Medium } \\
(\%)\end{array}$ & $\begin{array}{r}\text { Low } \\
(\%)\end{array}$ \\
\hline Supply of students & 55 & 32 & 13 \\
Career opportunities & 13 & 25 & 63 \\
Money to recruit students & 40 & 43 & 16 \\
Time required to recruit & 56 & 35 & 9 \\
State of the economy & 24 & 30 & 45 \\
College recruitment efforts & 18 & 58 & 24 \\
Salaries after graduation & 45 & 37 & 17 \\
Dept. programs & 13 & 30 & 56 \\
Industry cooperation & 5 & 48 & 46 \\
Lack of exposure & 41 & 51 & 7 \\
\hline
\end{tabular}

2Percentage of programs responding accordingly.

Table 6. Trend in backgrounds of horticulture students between 1983 and 1988.

\begin{tabular}{lccc}
\hline \hline & $\begin{array}{c}\text { Increased } \\
(\%)\end{array}$ & $\begin{array}{c}\text { Decreased } \\
(\%)\end{array}$ & $\begin{array}{c}\text { No change } \\
(\%)\end{array}$ \\
\hline Recently graduated from high school & 18 & 43 & 39 \\
Transfer from 2-year institution & 32 & 27 & 41 \\
Transfer from 4-year institution & 14 & 27 & 59 \\
Undecided major at your institution & 32 & 14 & 54 \\
Nontraditional (age 22-35) & 60 & 7 & 33 \\
Nontraditional (age 36 and older) & 40 & 4 & 56 \\
Student without prior & & 15 & 49 \\
$\quad$ horticultural experience & 36 & 13 & 54 \\
Part-time student & 34 & &
\end{tabular}

xPercentage of programs responding accordingly.

$85.7 \%$ correct for decreasing enrollment, $76.5 \%$ correct for increasing enrollment, and $66.7 \%$ correct for no change in enrollment.

Programs experiencing an increase in enrollment scored higher on Fn 1 than the other two groups. Programs showing no change in enrollment had Fn 1 scores closer to those of decreasing enrollment programs rather than increasing ones. This trend was also observed during the classification test when all of the misclassified no change programs were listed as declining programs.

Issues affecting future recruitment strategies. Each program was asked to rank the relative importance of 10 issues affecting future abilities to expand enrollment. A ranking of 1 to 3 was classified as high priority, 4 to 7 as medium priority, and 8 to 10 as low priority. The overall percentage of responses are shown in Table 5. Supply of students and time required to recruit were perceived by a majority of respondents to be high priority issues limiting future increases in enrollment. Money to recruit, salaries after graduation, and lack of exposure were perceived by many respondents to be high to medium priority. Career opportunities and departmental programs were perceived to be low priority.

A $\chi^{2}$ test was conducted on each issue to examine whether rankings differed according to enrollment trends. Only one question-money to recruit students-was found to differ significantly (data not presented). Programs with increasing enrollment rated the issue as medium priority, while declining enrollment programs rated the issue high priority.

Backgrounds of students. The background of students deciding to major in horticulture has been changing between 1983 and 1988
(Table 6). Just over $40 \%$ of all programs experienced a decrease in the percentage of new majors recently graduating from high school. However, more students have nontraditional backgrounds. They are age 22 and above, have no prior horticultural experience, and are only part-time students. Comparing overall enrollment trends to the backgrounds of students did not reveal any consistent pattern of behavior, with the exception of nontraditional students-age 36 and older (data not presented). The share of these students had increased in $50 \%$ of the declining enrollment programs compared to $33 \%$ for the increasing enrollment programs. None of the programs indicated any decrease in this type of student.

The issue of declining undergraduate enrollment in horticulture has previously been examined by Childers $(1986,1989 b)$ and Widmer (1988). However, these studies provided only a descriptive examination of the issue and did not examine the variety of recruitment strategies being used by departments. This study provides such information and can be used to evaluate future changes in enrollment and recruitment strategies.

While trends in overall enrollment and enrollment by area of specialization were identified, they are not exclusive to any given region of the country or size of program. In fact, this study found few geographical or program size differences in enrollment trends. However, enrollment in 1988 in large programs (> 81 students) was only $2.2 \%$ less than 1984 levels compared to an average decline of $25 \%$ for small to medium size programs ( 1 to 81 students).

Distribution of undergraduates among the various specialty areas is not uniform. Students specializing in landscape horticulture averaged $60 \%$ of total enrollment in 1988 , up from $56 \%$ in 1984. During this same time, share of enrollment in floriculture and pomology and olericulture declined.

Enrollment in horticulture increased in 39\% of all programs between 1986 and 1988 . While the distribution of increasing, decreasing, and no change programs was not significantly different between regions or program sizes, $70 \%$ of all large programs increased enrollment compared to an average of only $31 \%$ for the other size categories. Programs with increasing enrollment between 1986 and 1988 showed a net gain of 176 landscape horticulture and 33 floriculture majors but a loss of four pomology and olericulture majors. Programs with decreasing enrollment showed a net loss of 39 floriculture and 35 pomology and olericulture majors but a gain of 28 in landscape horticulture.

Recruiting students into horticulture takes time and effort. Of those reporting, 56\% rated this issue as a high priority in expanding enrollment (Table 5). However, enrollment trends and recruitment practices were shown to be related. Programs that experienced an increase in total enrollment between 1986 and 1988 were found to use various recruitment materials and activities more often than programs experiencing a decline in enrollment. Furthermore, the estimated discriminant functions successfully classified $85 \%$ of the decreasing enrollment programs using their current mix of recruitment materials and activities. Therefore, I recommend that recruiting strategies: a) develop materials that highlight departmental programs and career opportunities, e.g., handbooks, flyers, and videotapes; b) make these available to undecided majors, college and high school counselors, and alumni at career days; and c) provide travel funds for prospective students.

Survey respondents were asked to identify their most effective recruitment activity. These responses were characterized as either a direct or indirect approach. Having high school counselors, prospective students, and/or parents meet faculty during an open house program, presentation, or one-on-one discussion represents the direct approach. Having students and alumni, those having intimate knowledge of a program and its opportunities, act as goodwill ambassadors with prospective students represents the indirect approach. Either way, both approaches have been identified as very successful.

Finally, recruitment strategies need to be developed with a target audience in mind. Based upon past experience, the market for new majors will likely be undecided majors already on campus, older students (age 22 and higher), persons with no prior horticultural experience, and individuals wanting to enroll on a part-time basis. As a result, the content and approach of many programs may need to be modified to attract a nontraditional student. Courses that teach students the necessary practical skills required of a horticulturist may be needed, a series of internships may be necessary to expose new 
students to the seasonality of horticultural production and retailing, and course offerings may need to include an evening or weekend option to accommodate the parttime student. Implementing these recommendations will not guarantee an increase in enrollment, but combining a careful programmatic review with a consistent recruitment strategy is necessary if faculty want to maintain an undergraduate program in horticulture.

\section{Literature Cited}

Childers, N.F. 1986. Is there a crisis developing in horticulture? HortScience 21(1):8-9.

Childers, N.F. 1989a. Educational institutions offering horticulture and/or landscape architecture in the United States and Canada. HortScience 24(2):211-217.

Childers, N.F. 1989b. Accumulated philosophy on student recruiting, teaching, research, and funding in horticulture. HortScience 24(6):895896.
Hundley, M. 1988. Horticulture education: the good news. Soc. Amer. Florists December: 29-35.

Nefstead, W.E. 1988. Recruitment strategy with a detailed marketing plan. Nat. Assn. College Teachers of Agr. J. 32(1):26-30.

Norusis, M.J. 1986. SPSS/PC+ for the IBM PC/ XT/AT. SPSS, Chicago, Ill.

Widmer, R.E. 1988. U.S. floricultural education. HortScience 23(2):255-259. 